\title{
An overview of online trust: Concepts, elements, and implications
}

\author{
Ye Diana Wang *, Henry H. Emurian \\ Information Systems Department, College of Engineering and Information Technology, UMBC, \\ 1000 Hilltop Circle, Baltimore, MD 21250, USA
}

\begin{abstract}
Lack of trust has been repeatedly identified as one of the most formidable barriers to people for engaging in e-commerce, involving transactions in which financial and personal information is submitted to merchants via the Internet. The future of e-commerce is tenuous without a general climate of online trust. Building consumer trust on the Internet presents a challenge for online merchants and is a research topic of increasing interest and importance. This paper provides an overview of the nature and concepts of trust from multi-disciplinary perspectives, and it reviews relevant studies that investigate the elements of online trust. Also, a framework of trust-inducing interface design features articulated from the existing literature is presented. The design features were classified into four dimensions, namely (1) graphic design, (2) structure design, (3) content design, and (4) social-cue design. By applying the design features identified within this framework to e-commerce web site interfaces, online merchants might then anticipate fostering optimal levels of trust in their customers.
\end{abstract}

Keywords: Trust; Online trust; E-commerce; Interface design

\section{Introduction and background}

The phenomenal growth in the number of Internet users and the enormous potential of electronic commerce (e-commerce) via the Internet have attracted

\footnotetext{
*Corresponding author. Tel.: +1-410-455-3206; fax: +1-410-455-1073.

E-mail addresses: ywang8@umbc.edu (Y.D. Wang), emurian@umbc.edu (H.H. Emurian).
} 
merchants to conduct their businesses online. The Census Bureau of the Department of Commerce reported that the estimate of US retail e-commerce sales for the third quarter of 2002 was $\$ 11.061$ billion, an increase of $34.3 \%$ from the third quarter of 2001. ${ }^{1}$ However, while Internet technologies and infrastructures to support ecommerce are now in place and obviously being used by consumers, several recent surveys show that the majority of users of the Internet in the US are still hesitant about shopping online.

In one national survey of 1017 Internet users conducted by the Pew Internet and American Life Project (PIP), 68\% expressed concern about revealing financial information, but $48 \%$ had actually made a purchase online with a credit card; almost $3 \%$ reported being cheated by an online merchant or having had a credit card number stolen (Fox, 2000). The survey also reported that online consumer concerns were little different from those expressed about other merchants. In a more recent survey of 1677 Internet users conducted in October 2002, it was estimated that only $3 \%$ of 64 million Internet users in the US purchased a product online on an average day (PIP, 2002). In yet another national survey of 1500 Internet users conducted by Princeton Survey Research Associates (2002) for Consumer WebWatch, a project of Consumers Union, $64 \%$ of users expressed reservations about trusting e-commerce sites.

The most recent survey data on online purchasing were reported by PIP for the month of December 2002. Based on a national survey of 1220 Internet users, only $28 \%$ purchased holiday gifts online, and this projects to approximately 30 million purchasers (Rainie \&Horrigan, 2002). Taken together, the results from these several surveys suggest that consumer distrust regarding transactions on the Internet may hinder the future valuation of even the leading "dot.coms" (The Economist, 2001), and online merchants presently face a difficult challenge - to build consumer trust to make purchases on the Internet.

Trust with all of its connotations has been studied in numerous disciplinary fields, and it presents important research opportunities and applications in an online context. If online trust can be understood and enhanced by reputable online merchants, then the number of people who engage in e-commerce should increase substantially. More importantly, a general climate of trust online will be created in which buyers will feel more at ease in disclosing sensitive information, sellers will feel confident to conduct business online, and there will be intensive interactions, transactions, and associations to benefit consumers and merchants alike. Put simply, the future of e-commerce depends on trust, and at least one training organization, m-eTrust, ${ }^{3}$ now offers a certificate program purporting to teach the skills and competencies considered vital to implement and manage trustworthy e-commerce web sites.

\footnotetext{
${ }^{1}$ US Department of Commerce News: http://www.census.gov/mrts/www/current.html.

${ }^{2}$ Internet is used here to include the World Wide Web because that is now a common way to refer to the medium for electronic communications and information exchanges.

${ }^{3}$ http://www.m-etrust.com/.
} 
To build online trust, however, is a formidable task. Because trust is a complex and abstract concept, it is difficult to define trust and to identify the elements that construct it. Moreover, due to the nature of e-commerce, online merchants mainly depend on their web sites to represent themselves to consumers. As stated by Ang and Lee (2000), "If the web site does not lead the consumer to believe that the merchant is trustworthy, no purchase decision will result" (p. 3). Hence, there is a need to focus on web interface implications that online merchants can consider and adopt to enhance their perceived trustworthiness to potential customers.

Against that background, this paper has three objectives: (1) to provide an overview of various approaches in conceptualizing trust in multiple fields; (2) to examine the state of trust studies that investigate the elements of trust in online contexts; and (3) to articulate the existing web interface design implications, mostly based on human-computer interaction (HCI) knowledge, and propose a framework of design features that may be helpful to induce greater online trust.

The paper addresses the following questions. How is trust defined in both offline and online contexts? What are the characteristics of trust in both offline and online contexts? What are the elements, antecedents, underlying dimensions, determinants or principles of online trust? How can online merchants build consumer trust by web interface design? Online trust in this paper refers to consumer trust directed towards e-commerce web sites or merchants on the Internet and only applies to Business-toConsumer (B2C) e-commerce transactions. Finally, consumers' concerns about the ability of the Internet infrastructure in a technical sense and their perceptions of trustworthiness of an online merchant should be recognized as two distinct issues, and the latter issue is the focus of this paper.

The rest of the paper is organized as follows. First, a general overview of trust from the disciplines of philosophy, psychology, management, and marketing is provided to illustrate the nature and concept of trust. Based on this overview, diverse perspectives are integrated into a summary of characteristics of trust, and these characteristics are further elaborated in an online context. Following this, relevant studies are reviewed in an attempt to identify the elements that are pertinent to the formation of online trust. Next, a framework of trust-inducing features is proposed that is based on existing literature on enhancing online trust by web interface design. The paper concludes with suggestions for further research on online trust. Unless noted otherwise, the paper is based upon data collected from English speaking users of the Internet located within the US.

\section{The nature and concept of trust}

\subsection{The difficulty of defining trust}

Trust, according to the Oxford English Dictionary (1971), is defined as "confidence in or reliance on some quality or attribute of a person or thing, or the truth of a statement" (p. 3423). Trust has existed as long as the history of human beings and the existence of human social interactions. Almost every aspect of a person's life is 
based on some form of trust. Undoubtedly, trust is positive and vital to humanity since it is part of love and friendship, and meaningful relationships depend upon it. Presently, however, researchers have difficulty in operationalizing what exactly trust is, and they disagree even on basic definitions (e.g., Husted, 1998). This difficulty in defining trust is further evidenced by numerous researchers. For example, Shneiderman (2000) quoted definitions of trust published by a former US State Department Analyst (i.e., Fukuyama, 1995) and by computer scientists (i.e., Fogg \& Tseng, 1999) and also offered his own definition of trust. Additionally, Sirdeshmukh, Singh, and Sabol (2002) quoted two prior studies' definitions of trust (i.e., Moorman, Zaltman, \& Deshpande, 1992, p. 315; Morgan \& Hunt, 1994, p. 23) and also offered a definition of their own. Despite the Oxford Dictionary's definition, then, trust is often conceptualized by researchers according to the features of a particular context.

The presence of multiple definitions of trust in the literature is likely due to two reasons. First, trust is an abstract concept and is often used interchangeably with related concepts such as credibility, reliability, or confidence. Thus, to define the term and to delineate the distinction between trust and its related concepts have proven challenging for researchers. Second, trust is a multi-faceted concept that incorporates cognitive, emotional, and behavioral dimensions (Lewis \& Weigert, 1985). Trust has been widely studied in many disciplines, but each discipline has its own understanding of the concept and different ways to operationalize it. Writing from the perspective of a critical analysis of trustworthiness as security, Nissenbaum (2001) stated, "Trust is an extraordinarily rich concept, covering a variety of relationships, conjoining a variety of objects. One can trust (or distrust) persons, institutions, governments, information, deities, physical things, systems, and more" (p. 104). There is, then, a lack of consistent principles by which to define trust and all of its manifestations as the term may be used to characterize consumer-merchant relationships.

\subsection{A general overview of trust}

For obvious reasons, trust has been studied long before the emergence of the Internet or e-commerce and has been conceptualized within different disciplines. These trust studies mainly focus on trust in general (i.e., "offline trust") in attempts to provide a fundamental understanding of the concept and, therefore, they are important in grounding us to examine trust in the online world. To provide a general overview of trust and to illustrate the various approaches to the definition of trust, several examples are presented from the extensive literature in the disciplines of philosophy, psychology, management, and marketing.

\subsubsection{Philosophy}

In the discipline of philosophy, speculations on trust can be traced back to the ancient Greeks. Most ancient philosophers studied trust in an attempt to draw a picture of human nature (Bailey, 2002). The Greeks believed that people trust others only if people are confident that the others fear detection and punishment sufficiently to dissuade them from harming or stealing. In addition, they identified love and 
sympathy to be the elements that would ensure more trust and, therefore, more cooperation and peace, in a state of nature.

Modern philosophers, pioneered by Annette Baier, focused on interpersonal trust and the morality of trust relationships. Baier (1994) defined trust as the "accepted vulnerability to another's possible but not expected ill will toward one" (p. 99). Accepting trust as a three-place predicate (A trusts $B$ with valued thing $C$ ), she suggested that trustor A needed good judgment to know how much discretion to give. Because trustee $\mathrm{B}$ would have had discretionary powers over the entrusted valued thing $\mathrm{C}$, the trustor had to take the risk if the trustee abused the granted power.

Political philosophers have explored trust in terms of social values and benefits. For instance, Francis Fukuyama, in his politically oriented book entitled Trust, the Social Virtues and the Creation of Prosperity argued that "social capital is a capability that arises from the prevalence of trust in a society or in certain parts of it" (Fukuyama, 1995, p. 26). Spontaneous sociability engendered by trust is a mechanism by which values are shared and confirmed among group members.

\subsubsection{Psychology}

The majority of the psychology literature on trust has focused on interpersonal trust, but different approaches have been taken to study trust. Psychologists generally agreed that trust, especially interpersonal trust, was an important concept in psychology and vital to personality development (Erikson, 1963), cooperation institution (Deutsch, 1962), and social life (Rotter, 1980). Unlike philosophers, psychologists concentrated on individual differences in trust as personality characteristics and the consequences of such differences in early life and human relationships.

For example, psychoanalyst Erik Erikson defined trust as the first stage of his model of human development. He suggested that such "basic trust" was a central ingredient in the "healthy personality" and had a major impact on individual traits (Erikson, 1963, p. 7). Trust also plays an important role in establishing cooperative relationships. According to Deutsch, "the initiation of cooperation requires trust whenever the individual, by his choice to cooperate, places his fate partly in the hands of others" (Deutsch, 1962, p. 302).

A frequently cited definition of interpersonal trust was given by Rotter (1967), who defined trust as "an expectancy held by individuals or groups that the word, promise, verbal, or written statement of another can be relied on" (p. 651). The researcher pointed out that individuals differed in a generalized expectancy and developed a Likert-type scale to measure interpersonal trust. By conducting experiments, the researcher also confirmed the positive consequences of trust to people and overall society.

\subsubsection{Management}

In the discipline of management, trust has been studied intensively in organizational contexts. Scholars have investigated the roles and importance of trust in organizations (Kramer, 1999). Driscoll (1978) considered trust and participation as predictors of satisfaction in organizational decision making. Organizational trust was 
defined as "the belief that the decision makers will produce outcomes favorable to the person's interests without any influence by the person" (Driscoll, 1978, p. 44). As workforce composition increased in diversity and organizational structure changed, trust was also identified as a control mechanism for enabling employees to work together more productively and effectively (Mayer, Davis, \& Schoorman, 1995).

Another role of trust that had been recognized was to reduce the cost of both intra- and inter-organizational transactions (Uzzi, 1997). Management researchers generally believe that trust can enhance business performance. In addition, there has been interest in the link between inter-organizational trust and governance. For instance, Sako (1998) regarded trust as an informal governance structure, "which enhances the effectiveness of transactions whether they take place in markets or within a hierarchy" (p. 91). Finally, the relationship of employee trust in leadership with job satisfaction and organizational commitment has been reported in a recent meta-analysis of several decades of research (Dirks \& Ferrin, 2002).

\subsubsection{Marketing}

In the discipline of marketing, research on trust has been conducted within the context of distribution channels (e.g., manufacturer-retailer) and buyer-seller relationships. One particular area of research focused on how to maintain long-term relationships in distribution channel arrangements given the fact that the switching costs were relatively high. Kumar (1996) and other researchers agreed that trust, rather than power, helped manufacturers or retailers receive more tangible benefits and realize their full potential, thus facilitating long-term commitments.

Much attention on trust was drawn from relationship marketing perspectives. Relationship marketing focused not on discrete transactions, but rather on relational exchange, which was "longer in duration, reflecting an ongoing process" (Dwyer, Schurr, \&Oh, 1987, p. 23). Trust, defined as “a willingness to rely on an exchange partner in whom one has confidence” (Moorman, Deshpande, \& Zaltman, 1993, p. 90), had assumed an essential role in establishing and maintaining a long-term relationship between sellers and customers.

Scholars in this discipline primarily focused on two targets of trust: supplier firms and their sales people. A dominant view was given by Doney and Canon (1997): "customers can trust the supplier firm, its salesperson, or both" (p. 36). These investigators had further verified that some characteristics of salespersons, such as expertise, likeability, and similarity to customers, played a significant role in building trust and strengthening the link between the customer and the supplier firm. Finally, Sirdeshmukh et al. (2002) found that consumers' reports of the behavior of front-line employees and the practices and policies of management, both evaluated in terms of competency, benevolence, and problem solving, were related to reports of trust in the businesses under consideration.

\subsection{Characteristics of trust}

While acknowledging the diverse opinions of scholars and researchers in defining trust, this paper does not attempt to provide an explicit definition of trust. Instead, 
we attempt to integrate several emergent themes related to how trust was viewed from the selected studies in the previous section, particularly those revealing the nature of trust. This approach is intended to facilitate a better understanding of trust in an online context. Against that background, four characteristics of trust are generally observed and accepted by researchers studying trust:

1. Trustor and trustee. There must exist two specific parties in any trusting relationship: a trusting party (trustor) and a party to be trusted (trustee). The two parties, comprised of persons, organizations, and/or products, include an evaluation of the actions of each party. The development of trust is based on the ability of the trustee to act in the best interest of the trustor and the degree of trust that the trustor places on the trustee.

2. Vulnerability. Trust involves vulnerability. Trust is only needed, and actually flourishes, in an environment that is uncertain and risky. Trustors must be willing to make themselves vulnerable for trust to be operational by taking the risk of losing something important to them and relying on the trustees not to exploit the vulnerability.

3. Produced actions. Trust leads to actions, mostly risk-taking behaviors. The form of the action depends on the situation, and the action may concern something either tangible or intangible. For instance, a person lends his or her money to a friend because the friend is trusted to pay back the money later; a couple gets married because the parties trust each other to be loyal in the relationship.

4. Subjective matter. Trust is a subjective matter. It is directly related to and affected by individual differences and situational factors. Different people view the role of trust differently in different scenarios and have different magnitudes of trust towards different trustees.

\section{Online trust}

\subsection{Characteristics of online trust}

Online trust shares similar characteristics to those of offline trust, but there are some important distinctions that are unique in an online environment. These distinctions can serve as starting points for seeking a deeper understanding of the nature of trust in an online context. The characteristics of online trust can be described as follows:

1. Trustor and trustee. The two parties, trustor and trustee, are still vital for establishing a trusting relationship in the online world, but they imply specific entities. In the offline situation, the trustor and trustee positions can be filled by many different entities. In online trust, however, the trustor is typically a consumer who is browsing an e-commerce web site, and the trustee is the e-commerce web site, or more specifically, the merchant that the web site represents. Sometimes, the technology (mainly the Internet) itself is an object of trust (Marcella, 1999).

2. Vulnerability. Because of the high complexity and anonymity associated with ecommerce, merchants can behave in an unpredictable manner on the Internet. 
Consumers are often uncertain about the risks at present and their full consequences when transacting online. As stated by Gefen (2002), "Even when online consumers only examine a web site without purchasing from it, data may be automatically collected about their activities and later misused or distributed without their consent or knowledge" (p. 40). All these reasons contribute to an insecure environment where trust is needed and can potentially flourish, posing unique challenges to building and maintaining trust. Finally, in online commercial transactions, consumers are vulnerable to specific trust violations: loss of money and loss of privacy (Friedman, Howe, \& Kahn, 2000).

3. Produced actions. Consumer trust in online merchants generates two specific forms of action from the consumer: (1) making a purchase online from the merchant, presumably including providing credit card and personal information in the transaction, and (2) "window-shopping" at the merchant's web site. Either of these actions brings positive outcomes to online merchants, such as actual or potential sales. To engage in such activities, consumers must be confident that they have more to gain than to lose.

4. Subjective matter. Like offline trust that is associated with individual differences and situational factors, online trust is inherently a subjective matter (GrabnerKraeeter, 2002). The level of trust considered sufficient to make transactions online is different for each individual. People also hold different attitudes toward machines and technology.

\subsection{Elements of online trust}

Without attempting to identify the elements that are pertinent to the formation of online trust, it is difficult to derive effective and reliable design principles or implications on enhancing consumer trust in e-commerce. This section reviews relevant studies on the subject of these trust elements, which are often referred to interchangeably as antecedents, underlying dimensions, determinants, or principles of online trust. In general, these terms all refer to factors that can produce a sense of trustworthiness or even determine whether consumers will trust an online merchant's web site.

Gefen (2002) examined trust from a multi-dimensional perspective. According to the researcher, the specific beliefs of integrity, ability, and benevolence were seen as antecedents to overall trust. In the case of e-commerce, integrity was the belief that the online merchant adhered to stated rules or kept promises. Ability was the belief about the skills and competence of the online merchant to provide good quality products and services. Benevolence was the belief that the online merchant, aside from wanting to make legitimate profits, wanted to do good to the customer without regard to making a sale.

While holding a similar view, Ang, Dubelaar, and Lee (2001) proposed that three dimensions of trust were important for enhancing the perception of trust on the Internet. These three dimensions were the ability of the online merchant to deliver a product or service that performs as promised, the willingness of the online merchant to rectify should the purchase not meet the customer's satisfaction, and the presence of a privacy policy or statement on the web site. 
Based on the literature from multi-disciplines, Kim, Song, Braynov, and Rao (2001) investigated the determinants of online trust and divided the determinants into six dimensions, namely information content, product, transaction, technology, institutional, and consumer-behavioral dimensions. These dimensions, which were further broken down into many sub-dimensions or properties, formed a theoretical framework of online trust, covering the different stages that a consumer went through to complete an online transaction. In differing from most researchers, Kim et al. (2001) proposed that the consumer could perceive trust before, during, or after the online transaction. The researchers further concluded that different determinants of trust were associated with different stages of the transaction.

Lee and Turban (2001) posited that four main antecedents influenced consumer trust in Internet shopping. The antecedents were the trustworthiness of the Internet merchant, trustworthiness of the Internet as a shopping medium, infrastructual (contextual) factors (e.g., third-party certification), and other factors (e.g., company size). Given the fact that most researchers tended to ignore the role of the computer systems or the Internet through which transactions were executed and only focus on building trust between consumer and merchants, it was remarkable that Lee and Turban (2001) considered the perception of the shopping medium as a critical factor of consumer trust in Internet shopping. The researchers also pointed out that the individual's trust propensity ("trust baseline") could moderate the relationships between the antecedents of trust and trust itself.

Two other areas of research have been repeatedly cited and considered foundational, including the work by Egger (2001) and the Cheskin/Sapient Report (1999). The researchers both took a similar approach to formulate the factors that were likely to affect consumer trust or to communicate trustworthiness to consumers in ecommerce by constructing a model of trust. Egger's model is called the Model of Trust for Electronic Commerce (MoTEC). The model consists of four components: the pre-interactional filters taking place before any online interaction, the interface properties of the web site, the information content of the web site, and relationship management. The researcher stated that "relationship management reflects the facilitating effect of timely, relevant, and personalized merchant-buyer interactions on trust development and maintenance" (Egger, 2001, p. 6). The strength of this model is that it covers the entire buyer-seller interaction process, and it also places emphasis on the effects of customer relationship management. On the other hand, the Cheskin/Sapient Report (1999) focused on web site interface cues and presented a model of six building blocks of online trust. These six building blocks were seals of approval, brand, navigation, fulfillment, presentation, and technology. The building blocks could be further divided into a total of 28 components to establish perceived trustworthiness.

More recently, Hemphill (2002) conceptualized the foundation of online trust in terms of five fair information practice principles. Three principles are relevant to the design of a web site. It was argued that an online merchant should post the business's policies on disclosure of personal information, provide options for how a consumer's personal data might be used in other contexts, and allow consumers to access and view personal data. Importantly, the author argued that "without an enforcement 
and redress mechanism, a fair information practice code is merely a suggested set of guidelines rather than a prescriptive mechanism, and does not ensure compliance with the fair information practice principles" (Hemphill, 2002, p. 2).

Hemphill (2002) was one of the few scholars in this area who considered and discussed the necessity of legislation to create civil remedies for consumers in the event of untrustworthy interactions with an online merchant. Consistent with that approach, the author noted the Online Privacy Act of 1998 and the Gramm-Leach-Bliley Act of 1999, together with recent Federal Trade Commission suits against several online merchants (e.g., Toysmart.com) for committing privacy violations. Even with such regulations, however, online consumers still require protection from deceptive web sites, and effective design might be anticipated to contribute to that outcome.

A final study to be considered is that reported by Ba and Pavlov (2002). Using 95 experienced eBay buyers, self-reports of trust in a seller's credibility were found to be sensitive to experimental manipulations of positive and negative feedback about the seller. Positive feedback was associated with greater trust in a seller than was negative feedback, presented to the buyer subjects as experimenter-controlled reputation profiles. Although the effects on trust were demonstrated by profile differences, at issue was the buyer's trust in the accuracy of the profiles themselves. Against the background of guidelines, surveys, and models, this was a rare experimental evaluation of a trust-inducing mechanism.

These preceding studies provide important insights into the elements of online trust. However, because the study of trust in an online context is relatively new, there are several consistent issues that exist across most of the studies. As mentioned earlier, the terms element, antecedent, dimension, determinant, and principle are sometimes used interchangeably due to the lack of agreement among researchers in the field on a clear definition for each term. A similar observation was made by Shankar, Urban, and Sultan (2002) regarding trust studies in the information systems and e-business literature. In addition, researchers sometimes propose a list of trust-inducing features in their studies without providing empirical evidence for the relative importance of each feature to the establishment of trust.

There are exceptions, however, to include the study of over 4500 people by Fogg (2002) and his associates, who offer 10 specific research-based guidelines for fostering credibility on a web site, e.g., "Make it easy to verify the accuracy of the information on your site." Although this investigator and his colleagues make a distinction between trust and credibility (e.g., Fogg \& Tseng, 1999), trustworthiness is viewed as a dimension of credibility, and the analyses contribute to the knowledge about trust. Furthermore, the survey by Princeton Survey Research Associates (2002) also reported several specific types of posted information (e.g., a privacy policy) that were said to be valued by Internet users.

Despite these surveys and the experimental work of $\mathrm{Ba}$ and Pavlov (2002), the guidelines proposed for trustworthy e-commerce web sites largely reflect the opinions of the researchers, which are often in response to survey data about the reported concerns of e-commerce consumers rather than to the purchasing actions of consumers. This is the current body of work from which any potential implementation is to be derived. 


\section{Implications for web interface design}

\subsection{Build online trust by web interface design}

Based on the accumulated knowledge and understanding of the elements of online trust in the previous section, online merchants can take many managerial measures to build and enhance merchant-customer relationships before, during, and/or after any online transaction, which can increase consumers' trust. While those managerial measures might be useful in retaining loyal customers, online merchants need more efficient ways to convey their trustworthiness to first-time visitors and to transform them into consumers. Moreover, the physical appearances of business buildings and facilities, together with the direct contact with company employees, which have been found to have effects on consumer trust in a conventional business context, are missing in the online environment. Online merchants depend primarily on their electronic storefront to attract potential customers and to communicate with them. Therefore, applying trust-inducing features to the web sites of online merchants is the most effective method of enhancing online trust, given the current state of knowledge.

In a sense, a web site with trust-inducing features functions as a skillful salesperson for the company (Jarvenpaa, Tractinsky, \& Saarinen, 1999) and, therefore, moderates the disadvantages of an impersonal web site. Karvonen (2000) also reported that Internet users admitted to making intuitive, and rather emotional, onthe-spot decisions based on their perceptions of an online merchant's web site when shopping online. Finally, as discussed by Kubilus (2002), the implementation of a trustworthy e-commerce interface will share many of the general design features for effective interface usability (e.g., Neilsen, 2000) when applied to e-commerce web sites (Scheffelmaier \& Vinsonhaler, 2002).

\subsection{A framework of trust-inducing features}

In this section, a framework of trust-inducing features is proposed in an effort to synthesize existing literature on enhancing online trust by web interface design. This growing body of the literature, mainly in the field of HCI, focuses on how to design web sites that are perceived by consumers as trustworthy, rather than using technological mechanisms to build strong infrastructures. In other words, the main goal for related HCI researchers was to explore web interface design implications to maximize consumer trust or, more precisely, trust perception. The implications to be presented are to be understood in terms of optimally representing the information associated with many of the trust-inducing elements discussed previously. The framework classifies these trust-inducing features into four broad dimensions as shown in Table 1. The four dimensions are discussed next.

\subsubsection{Graphic design dimension}

This dimension refers to the graphical design features on the web site that normally give consumers their first impression. In an experimental investigation of 
Table 1

Framework of trust-inducing features

\begin{tabular}{|c|c|c|c|}
\hline Dimension & Explanation & Features & Literature sources \\
\hline $\begin{array}{c}\text { Graphic } \\
\text { design }\end{array}$ & $\begin{array}{l}\text { Refers to the graphical } \\
\text { design factors on the web } \\
\text { site that normally give } \\
\text { consumers a first } \\
\text { impression }\end{array}$ & $\begin{array}{l}\text { - Use of three-dimensional, } \\
\text { dynamic, and half-screen } \\
\text { size clipart } \\
\text { - Symmetric use of moderate } \\
\text { pastel color of low brightness } \\
\text { and cool tone } \\
\text { - Use of well-chosen, } \\
\text { good-shot photographs }\end{array}$ & $\begin{array}{l}\text { Karvonen and } \\
\text { Parkkinen (2001); Kim } \\
\text { and Moon (1998) }\end{array}$ \\
\hline $\begin{array}{r}\text { Structure } \\
\text { design }\end{array}$ & $\begin{array}{l}\text { Defines the overall } \\
\text { organization and } \\
\text { accessibility of } \\
\text { displayed information } \\
\text { on the web site }\end{array}$ & $\begin{array}{l}\text { - Implementation of } \\
\text { easy-to-use navigation } \\
\text { (simplicity, consistency) } \\
\text { - Use of accessible information } \\
\text { (e.g., no broken links and } \\
\text { missing pictures) } \\
\text { - Use of navigation reinforce- } \\
\text { ment (e.g., guides, tutorials, } \\
\text { instructions) } \\
\text { - Application of page design } \\
\text { techniques (e.g., white space } \\
\text { and margin, strict grouping, } \\
\text { visual density) }\end{array}$ & $\begin{array}{l}\text { Cheskin/Sapient Report } \\
\text { (1999); Karvonen and } \\
\text { Parkkinen (2001); } \\
\text { Neilsen (1998); Zhang, } \\
\text { von Dran, Small, and } \\
\text { Barcellos (1999) }\end{array}$ \\
\hline $\begin{array}{l}\text { Content } \\
\text { design }\end{array}$ & $\begin{array}{l}\text { Refers to the } \\
\text { informational } \\
\text { components that can } \\
\text { be included on the } \\
\text { web site, either } \\
\text { textual or graphical }\end{array}$ & $\begin{array}{l}\text { - Display of brand-promoting } \\
\text { information (e.g., prominent } \\
\text { company logo or slogan, } \\
\text { main selling point) } \\
\text { - Up-front disclosure of all } \\
\text { aspects of the customer } \\
\text { relationship (e.g., company } \\
\text { competence, security, } \\
\text { privacy, financial, or legal } \\
\text { concerns) } \\
\text { - Display of seals of approval } \\
\text { or third-party certificate } \\
\text { - Use of comprehensive, } \\
\text { correct, and current } \\
\text { product information } \\
\text { - Use of a relevant domain } \\
\text { name }\end{array}$ & $\begin{array}{l}\text { Belanger, Hiller, and } \\
\text { Smith (2002); Cheskin/ } \\
\text { Sapient Report (1999); } \\
\text { Egger (2001); Hu, Lin, } \\
\text { and Zhang (2001); } \\
\text { Neilsen (1999); } \\
\text { Shneiderman (2000) }\end{array}$ \\
\hline $\begin{array}{c}\text { Social-cue } \\
\text { design }\end{array}$ & $\begin{array}{l}\text { Relates to embedding } \\
\text { social cues, such as } \\
\text { face-to-face interaction } \\
\text { and social presence, } \\
\text { into web interface via } \\
\text { different communication } \\
\text { media }\end{array}$ & $\begin{array}{l}\text { - Inclusion of representative } \\
\text { photograph or video clip } \\
\text { - Use of synchronous } \\
\text { communication media (e.g., } \\
\text { instant messaging, chat lines, } \\
\text { video telephony) }\end{array}$ & $\begin{array}{l}\text { Basso, Goldberg, } \\
\text { Greenspan, and } \\
\text { Weimer (2001); } \\
\text { Riegelsberger and Sasse } \\
\text { (2001); Steinbruck, } \\
\text { Schaumburg, Duda, } \\
\text { and Kruger (2002) }\end{array}$ \\
\hline
\end{tabular}

alternative cyber-banking system interfaces conducted in Korea, Kim and Moon (1998) reported that the main clipart and overall color layout affected the trustworthiness of the web site. By operationalizing trustworthiness in terms of users' 
self-reports of the reliability and dependability of alternative interface designs, the researchers found that using three-dimensional, dynamic clipart that covered at least half of the total screen size could enhance the trustworthiness of a web interface. They also concluded that some attributes of interface color conveyed trustworthiness. For example, the tone of the interface color should be cool, and its main color should be a moderate pastel color. Additionally, the colors should be of low brightness and symmetrical.

The use of real photographs, rather than cartoons, was recommended by Karvonen and Parkkinen (2001). Generally, high-quality photographs of products and well-chosen images generate consumer confidence that can be transferred to other aspects of the web site. As Basso et al. (2001) indicated, "web retailers use eyecatching graphics not only to grab a user's attention but also to convey competence or professionalism" (p. 138). However, overuse of graphics will not help, but may damage the professional impression of a web site. As Lightner (2003) reported, mature and affluent users of e-commerce web sites tended to favor the absence of gratuitous sensory impact.

Finally, an analysis of the comments of 2440 Internet users regarding factors that promote the credibility of a web site, concluded that "nearly half of all consumers (or 46.1\%) in the [Stanford Persuasive Technology Lab] SPT study assessed the credibility of sites based in part on the appeal of the overall visual design of a site, including layout, typography, font size, and color schemes" (Stanford Persuasive Technology Lab, 2002).

\subsubsection{Structure design dimension}

This dimension defines the overall organization and accessibility of displayed information on the web site. Ease of navigation was frequently mentioned as a key to promote online trust (e.g., Cheskin/Sapient Report, 1999; Neilsen, 1998). In other words, users can easily locate the information they seek on the web site. This easeof-use reflects two characteristics of a trustworthy web site: simplicity and consistency. Consumers appreciate simplicity or a clear design of e-commerce web sites because it reduces the perceived risks of wasting time, deception, and frustration. Consumers could get annoyed when they see the design and format of interface elements varying from page to page within a site. When the structure and design of the web site are consistent, "users feel more confident using the site because they can transfer their learning from one sub-site to the next rather than having to learn everything over again for each new page” (Neilsen, 1998, p. 107).

Accessibility of the information on a web site is also instrumental to the establishment of online trust. For example, broken links, meaningless images, and similar "hygiene factors" may relate to users' dissatisfaction with a web site interface (Zhang et al., 1999). Additionally, the Cheskin/Sapient Report (1999) indicated that navigation reinforcement, such as prompts, guides, tutorials, and instructions, could aid and inform users to seek information or to perform transactions on the web site and, hence, promoted consumer trust. And the application of page design techniques that can increase readability, such as appropriate amount of white space and margins, strict grouping, and visual density, also help to increase the overall trustworthiness 
of the web site (Karvonen \& Parkkinen, 2001). Online consumers may report the importance of such factors as privacy policies, but their intention to purchase and their buying behavior suggest that the design of a web site has a major influence on the decision to use it (Belanger et al., 2002).

\subsubsection{Content design dimension}

This dimension refers to the informational components that can be included on the web site, either textual or graphical. Several researchers stress the importance of "branding" in e-commerce, which is to promote the brand reputation of a company online. Egger (2001) suggested two ways to do so: (1) displaying a prominent logo and slogan to facilitate the easy identification of the company, and (2) presenting the company's main selling point to arouse people's curiosity. The up-front disclosure of all aspects of the customer relationship was also considered important by numerous researchers (e.g., Cheskin/Sapient Report, 1999; Egger, 2001; Neilsen, 1999; Shneiderman, 2000) to build consumer trust in an online environment. These aspects of the customer relationship can be classified as company competence, security, privacy, financial, and legal responsibilities. To verify its competence, an online merchant can provide company background and contact details or disclose patterns of past performance and references from past and current customers on the web site. To address the remaining customer relationship aspects through the web site, an online merchant can provide links to security and privacy policies, offer tracking information, state the return policy, reveal shipping charges, and explain contractual terms.

The incorporation of seals of approval or third-party certificates into content design has been widely accepted as a strategy to assure consumers that the web sites are trustworthy. These assurance symbols, whether in the form of a logo or statement, have been proven to be useful in establishing online consumer trust through trusted third parties (TTPs), such as BBBOnLine, ${ }^{4}$ TRUSTe, ${ }^{5}$ and VeriSign. ${ }^{6}$ The study of $\mathrm{Hu}$ et al. (2001) classified the trusted seals into five types based on their functionality, namely protecting privacy, providing security, demonstrating consumer satisfaction, providing reliability, and providing assurance or guarantee. They also confirmed that displaying a trusted seal could promote online trust and influence consumers' willingness to shop online. The other trust-inducing features in this dimension include providing comprehensive, correct, and current product information and using a domain name consistent with the brand or company name (Egger, 2001; Neilsen, 1999).

\subsubsection{Social-cue design dimension}

This dimension relates to embedding social cues, such as face-to-face interaction and social presence, into web site interfaces via different communication media. Because a lack of the "human touch" or presence may constitute a barrier for at least

\footnotetext{
${ }^{4}$ http://www.bbbonline.org/.

${ }^{5}$ http://www.truste.org/.

${ }^{6}$ http://www.verisign.com/.
} 
some consumers to trust online merchants (e.g., Riegelsberger \& Sasse, 2002), several researchers have investigated the possibility of bringing consumer online experiences closer to interpersonal, face-to-face level interactions. This approach has been referred to as "virtual re-embedding" (Riegelsberger \& Sasse, 2002; Steinbruck et al., 2002).

Using walkthroughs by 15 users as a method for evaluating reactions to social cues (i.e., photographs and names of customer service agents, chat and call-back opportunities, photographs of the company, and photographs of a customer receiving an item) displayed on mock-up e-commerce interfaces, Riegelsberger and Sasse (2001) reported that medium experienced users responded favorably to photographs as trust inducing factors. Social cues that were functional, such as chat and call-back opportunities, were valued highest. Riegelsberger and Sasse (2002) subsequently reported a protocol analysis of 15 users' impressions of four mock-ups of the German online shopping site Amazon.de, all of which displayed a photograph, usually of a person. Photographs on the web site were evaluated positively for experienced shoppers if the photograph was appropriate to the brand. However, non-shoppers with pre-existing low levels of general trust perceived photographs of people as a manipulative ploy.

In an experiment in Germany that studied 45 users' responses on a trust questionnaire to three mock-up versions of an online-bank web site, Steinbruck et al. (2002) found that the web sites displaying a photograph of the company's representative produced higher trust reports than did the web site lacking a photograph. Including a photograph of a person, then, might be a simple but effective technique to increase the trustworthiness of an online merchant.

In addition, the interactivity of communication media was found to influence consumer trust (Basso et al., 2001). Synchronous communication media, such as instant messaging or video telephony, which "provides opportunities for real-time feedback and thus minimizing misunderstandings and demonstrating attentiveness" (Basso et al., 2001, p. 138), increases judgments of the trustworthiness of the salesperson and the online merchant.

Although the findings from these studies do favor the use of photographs overall, there are complex interactions between the display of real images on an e-commerce web site and the prior experiences and the current objectives of the users. It should be emphasized, then, that the studies on applying social cues, especially photographs, to web site design are still in a preliminary stage. However, the researchers do present a potentially effective approach to enhance online trust by adding a surrogate human presence and actual contact opportunities to the otherwise impersonal e-commerce interface.

\subsubsection{Example}

A single e-commerce web site was chosen to illustrate some of design features discussed in the above framework. Fig. 1 presents the web site for Saks Fifth Avenue, ${ }^{7}$ represented in gray tones. The interface is presented in muted colors on the web.

\footnotetext{
${ }^{7}$ http://www.saksfifthavenue.com/.
} 


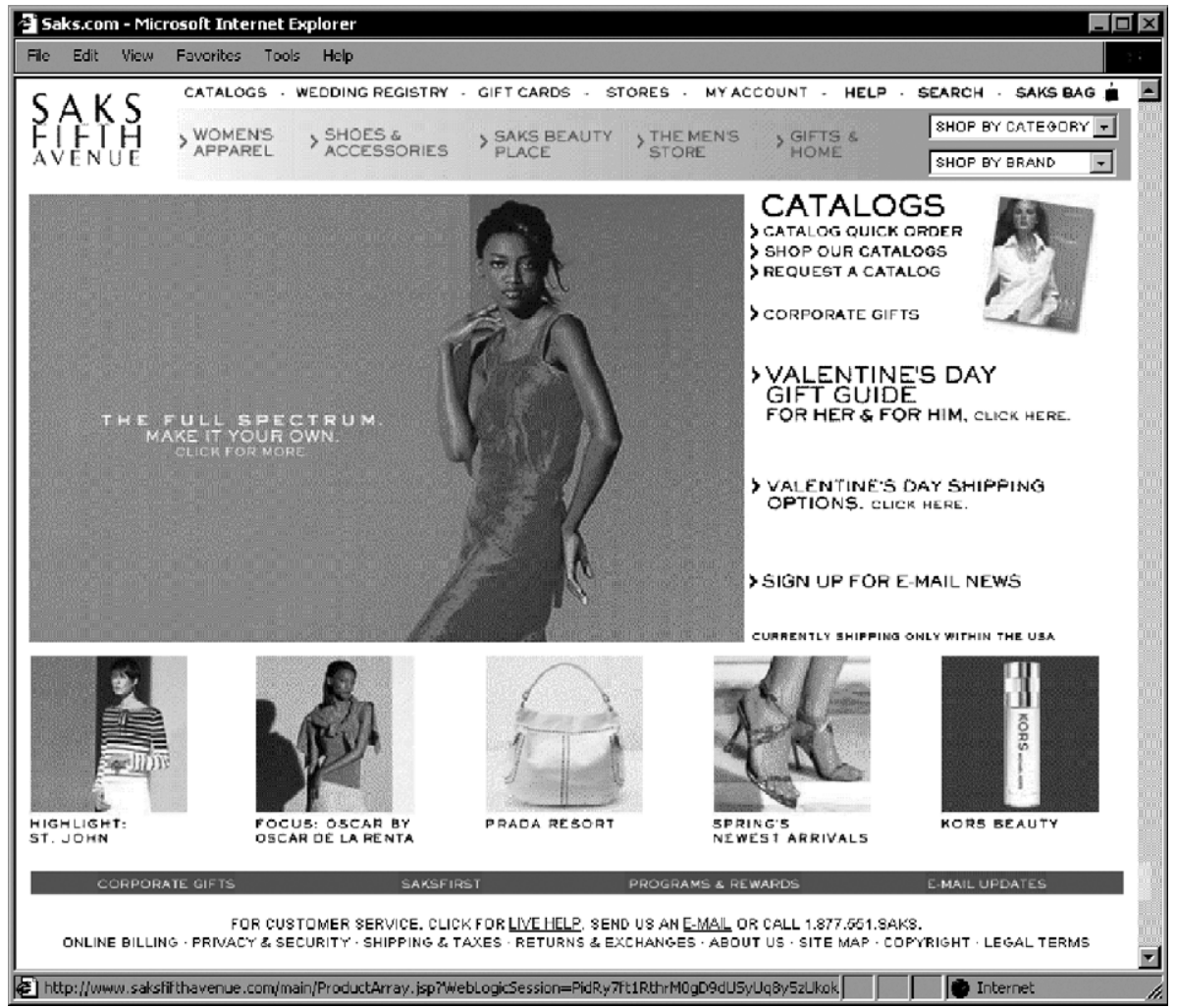

Fig. 1. Saks.com e-commerce interface. Reproduced with permission of Saks Fifth Avenue.

In terms of the graphic dimension, this interface has graphics on roughly half $(48 \%)$ of the page. There are photographs displayed of products as well as people. In terms of the structure design dimension, the interface appears to be uncluttered and concise, thereby exhibiting simplicity, although this judgment is subjective and not based upon information density or complexity metrics studied elsewhere (e.g., Emurian, 1994; Emurian \& Gonce-Winder, 1994; Emurian \& Seborg, 1990). Text and image links are arranged in an orderly vertical or horizontal fashion, an arrangement that minimizes information complexity, and the text describing products is larger than the text for other features of the site, such as "EMAIL UPDATES" and "Catalogs." Deeper in the site, the consistency of the interface is evidenced by the common links at the top and bottom of each page. Product photographs and links are consistently positioned within the center section.

In terms of the content design dimension, the Saks brand logo is clearly visible in the upper left corner of each page. All aspects of the consumer-merchant relationship are presented at the bottom of each page. Included there are links to statements about privacy and return policies, among other types of information. However, there is no seal of approval concerning privacy or security from an independent 
certification of the web site. In terms of the social-cue design dimension, there is a link on the web site to a chat-line with a sales representative. Also presented are an email address and an 800 telephone number.

The features represented in the Saks web site, then, illustrate many of the factors considered instrumental in a merchant's design of a trustworthy e-commerce interface.

\section{Conclusion and future directions}

Lack of trust has been repeatedly identified as one of the most formidable barriers to people for engaging in e-commerce, involving the disclosure of financial and personal information to online merchants (Hoffman, Novak, \& Peralta, 1999). The future of e-commerce is tenuous without a general climate of online trust. Hence, building and sustaining consumer trust on the Internet present a considerable challenge for online merchants and is a research topic of increasing interest and importance.

This paper provided an overview of the nature and concepts of trust from multiple disciplinary perspectives, and it reviewed the relevant studies that investigate the elements of online trust. Also, a framework of trust-inducing features articulated from existing literature was proposed. The design features have been synthesized and classified into four dimensions, namely graphic design, structure design, content design, and social-cue design. This framework, though still preliminary and in need of refinement and evaluation, suggests how to implement trust-inducing features in furtherance of enhancing online trust by web interface design. Finally, other researchers are also developing frameworks from their interpretation of the literature, and, for example, Nah and Davis (2002) proposed a model based on web site content, design, and external certifications and references.

Other approaches to enhancing trust between consumers and online merchants, such as the development and use of "Internet Trust Brokers" discussed by Fukuyama (2001), were not considered within the current framework. An example of a type of such a broker is ePublicEye.com, which collects data from online consumers and posts evaluations of vendors offering various categories of goods and services online.

Online trust has become a prominent research topic, and it offers promising opportunities for further research. Based upon the present overview, five potential areas of suggested research include: (1) the effects of culture on online trust; (2) the effects of domain (.com, .edu, .org) on online trust; (3) the reasons for losing online trust and the ways to repair it; (4) the importance of civil remedies for consumers in case of violations of privacy laws; and (5) the transferability of online trust from the Internet to other activities. A more extensive, but somewhat different, set of future directions for research was suggested by Shankar et al. (2002) who proposed eight avenues of potential investigation based on their analysis of multi-stakeholder factors in online trust. In addition, there is obvious need for more comprehensive frameworks to model online trust and more empirical evaluations, rather than survey-based and hypothetical approaches, to include the present formulation. The 
present framework is not exhaustive in the sense that it does not intend to capture every trust-inducing feature that web designers can apply. It only suggests a starting point for experimental evaluations and validations of its components. Finally, it should be pointed out that while well-crafted web interfaces can induce those who intend to purchase online, online merchants should also pay attention to other methods, such as customer relationship management (CRM) and offline marketing strategies, to obtain consumer trust and nurture strong business relationships (Tan, Yen, \& Fang, 2002).

Even when an interface is optimized to induce trust, the safety and benefits of ecommerce will still require an educated consumer who is informed about the risks and protections that are present in such transactions. The fact that few consumers have reported problems with online shopping and that known violations of consumer privacy have resulted in publicized actions taken against untrustworthy merchants bodes well for the future of e-commerce. Since a person's degree of trust, commonly called individual trust propensity, is a dynamic function of actions and consequences over time (e.g., Boyle \& Bonicich, 1970; Diller, Lin, \& Tashjian, 2003), it will be the consumer having trust-confirming experiences with online merchants who will sustain e-commerce on the Internet.

\section{Acknowledgements}

The authors appreciate the assistance of Mary Madden, Pew Internet and American Life Project, who clarified our interpretation of the survey data and who improved our presentation of that material.

\section{References}

Ang, L., Dubelaar, C., \& Lee, B.-C. (2001).To trust or not to trust? A model of internet trust from the customer's point of view. In Proceedings of the 14th Bled Electronic Commerce Conference (pp. 40-52), Bled, Slovenia.

Ang, L., \& Lee, B.-C. (2000). Influencing perceptions of trustworthiness in Internet commerce: A rational choice framework. In Proceedings of Fifth CollECTer Conference on Electronic Commerce (pp. 1-12), Brisbane.

Ba, S., \& Pavlov, P. A. (2002). Evidence of the effect of trust building technology in electronic markets: Price premiums and buyer behavior. MIS Quarterly, 26(3), 243-268.

Baier, A. C. (1994). Moral prejudices: Essays on ethics. Cambridge: Harvard University Press.

Bailey, T. (2002). On trust and philosophy. The philosophy of trust [WWW page], Open University Reith Lectures 2002. Available: http://www.open2.net/trust/on_trust/on_trust1.htm.

Basso, A., Goldberg, D., Greenspan, S., \&Weimer, D. (2001). First impressions: Emotional and cognitive factors underlying judgments of trust e-commerce. In Proceedings of the 3rd ACM Conference on Electronic Commerce (pp. 137-143). Tampa, FL, USA.

Belanger, F., Hiller, J. S., \& Smith, W. J. (2002). Trustworthiness in electronic commerce: The role of privacy, security, and site attributes. Journal of Strategic Information Systems, 11, 245-270.

Boyle, R., \& Bonicich, C. (1970). The development of trust and mistrust in mixed-motives games. Sociometry, 33, 123-139.

Cheskin Research and Studio Archetype/Sapient. (1999). Ecommerce trust study [PDF file]. Available: http://www.cheskin.com/p/ar.asp?mlid 1/4 7\&arid 1/4 40\&art $1 / 40$. 
Deutsch, M. (1962). Cooperation and trust: Some theoretical notes. Nebraska Symposium on Motivation, $10,275-318$.

Diller, S., Lin, L., \& Tashjian, V. (2003). The evolving role of security, privacy, and trust in a digitized world. In J. A. Jacko \& A. Sears (Eds.), The human-computer interaction handbook: Fundamentals, evolving technologies and emerging applications (pp. 1213-1215). Mahwah, NJ: Lawrence Erlbaum Associates.

Dirks, K. T., \& Ferrin, D. L. (2002). Trust in leadership: Meta-analytic findings and implications for research and practice. Journal of Applied Psychology, 87(4), 611-628.

Doney, P. M., \&Canon, J. P. (1997). An examination of the nature of trust in buyer-seller relationships. Journal of Marketing, 61(2), 35-51.

Driscoll, J. W. (1978). Trust and participation in organizational decision making as predictors of satisfaction. Academy of Management Journal, 21(1), 44-56.

Dwyer, R. F., Schurr, P. H., \&Oh, S. (1987). Developing buyer-seller relationships. Journal of Marketing, 51(3), 22-27.

Egger, F. N. (2001). Affective design of e-commerce user interface: How to maximize perceived trustworthiness. In Proceedings of the International Conference on Affective Human Factors Design. London: Asean Academic Press.

Emurian, H. H. (1994). Effects of format complexity on user performance and facial electromyographic activity: II. Computers in Human Behavior, 1994(10), 281-297.

Emurian, H. H., \& Gonce-Winder, C. (1994). Effects of format complexity on user performance and facial electromyographic activity: I. Computers in Human Behavior, 10, 261-280.

Emurian, H. H., \& Seborg, B. H. (1990). Some effects of row, diagonal, and column screen formats on search time and strategy. Computers in Human Behavior, 6, 153-166.

Erikson, E. H. (1963). Childhood and society (2nd ed.). New York: W.W. Norton.

Fogg, B. J. (May 2002). Stanford Guidelines for Web Credibility. A Research Summary from the Stanford Persuasive Technology Lab. Stanford University [WWW page]. Available: http://www.webcredibility.org/guidelines.

Fogg, B., \& Tseng, H. (1999). The elements of computer credibility. In Proceedings of CHI'99. New York: ACM Press.

Fox, S. (2000). Trust and privacy online: Why Americans want to rewrite the rules [PDF file], The Pew Internet \& American Life Project, Washington, DC. Available: http://www.pewinternet.org/reports/ pdfs/PIP_Trust_Privacy_Report.pdf.

Friedman, B., Howe, D., \& Kahn, P. (2000). Trust online. Communications of the ACM, 43(12), 34-40.

Fukuyama, F. (1995). Trust: The social virtues and the creation of prosperity. New York: Free Press.

Fukuyama, F. (2001). The virtual handshake: E-commerce and the challenge of trust [WWW page], The Merrill Lynch Forum. Available: http://www.ml.com/woml/forum/.

Gefen, D. (2002). Reflections on the dimensions of trust and trustworthiness among online consumers. ACM SIGMIS Database, 33(3), 38-53.

Grabner-Kraeeter, S. (2002). The role of consumers' trust in online-shopping. Journal of Business Ethics, $39,43-50$.

Hemphill, T. A. (2002). Electronic commerce and consumer privacy: Establishing online trust in the US digital economy. Business and Society Review, 107(2), 221-239.

Hoffman, D. L., Novak, T. P., \& Peralta, M. (1999). Building consumer trust online. Communications of the ACM, 42(4), 80-85.

Hu, X., Lin, Z., \&Zhang, H. (2001). Myth or reality: Effect of trust-promoting seals in electronic markets. Presented at WITS 2001. New Orleans, LA, USA.

Husted, B. (1998). The ethical limits of trust in business relations. Business Ethics Quarterly, 8(2), 233-248.

Jarvenpaa, S. L., Tractinsky, J., \& Saarinen, L. (1999). Consumer trust in an Internet store: A crosscultural validation. Journal of Computer Mediated Communication [on-line serial], 5(2). Available: http://www.ascusc.org/jcmc/vol5/issue2/jarvenpaa.html.

Karvonen, K. (2000). The beauty of simplicity. In Proceedings of the ACM Conference on Universal Usability. Arlington, VA: The Association of Computing Machinery.

Karvonen, K., \& Parkkinen, J. (2001). Signs of trust. In Proceedings of the 9th International Conference on HCI. New Orleans, LA, USA. 
Kim, J., \& Moon, J. Y. (1998). Designing towards emotional usability in customer interfaces trustworthiness of cyber-banking system interfaces. Interacting with Computers, 10, 1-29.

Kim, D., Song, Y., Braynov, S., \& Rao, H. (2001). A B-to-C trust model for on-line exchange. In Proceedings of Americas Conference on Information Systems (pp. 1-3), Boston, MA, USA.

Kramer, R. M. (1999). Trust and distrust in organizations: Emerging perspectives, enduring questions. Annual Review of Psychology, 50, 569-598.

Kubilus, N. J. (2002). Designing an e-commerce site for users. ACM Crossroads [on-line serial], August. Available: http://www.acm.org/crossroads/xrds7-1/ecuser.html.

Kumar, N. (1996). The power of trust in manufacturer-retailer relationships. Harvard Business Review, 74, 92-106.

Lee, M. K. O., \& Turban, E. (2001). A trust model for consumer internet shopping. International Journal of Electronic Commerce, 6(1), 75-91.

Lewis, J. D., \& Weigert, A. (1985). Trust as a social reality. Social Forces, 63, 967-985.

Lightner, N. J. (2003). What users want in e-commerce dsign: Effects of age, education and income. Ergonomics, 46(1), 153-168.

Marcella, A. J. (1999). Establishing trust in vertical markets. Altamonte Springs, FL: The Institute of Internal Auditors.

Mayer, R. C., Davis, J. H., \& Schoorman, F. C. (1995). An integrative model of organizational trust. Academy of Management Review, 20(3), 709-734.

Moorman, C., Deshpande, R., \& Zaltman, G. (1993). Factors affecting trust in market research relationships. Journal of Marketing, 57(1), 81-101.

Moorman, C., Zaltman, G., \& Deshpande, R. (1992). Relationships between providers and users of market research: The dynamics of trust within and between organizations. Journal of Marketing Research, 29(August), 314-328.

Morgan, R. M., \& Hunt, S. D. (1994). The commitment-trust theory of relationship marketing. Journal of Marketing, 58(July), 20-38.

Nah, F. F.-H., \& Davis, S. (2002). HCI research issues in e-commerce. Journal of Electronic Commerce Research, 3, 98-113.

Neilsen, J. (1998). Introduction to web design. In Proceedings of the Conference on CHI 98 Summary. Los Angeles, CA, USA.

Neilsen, J. (1999). Trust or bust: Communicating trustworthiness in web design. Jacob Nielsen's Alertbox [Web page]. Available: http://www.useit.com/alertbox/990307.html.

Neilsen, J. (2000). Designing web usability: The practice of simplicity. Indianapolis: New Riders Publishing.

Nissenbaum, H. (2001). Securing trust online: Wisdom or oxymoron? Boston University Law Review, 81, 101-131.

Oxford English Dictionary, The Compact Edition. (1971). New York: Oxford University Press.

PIP (2002). Pew Internet \& American Life Project Tracking surveys, October 7-27, 2002 [WWW page]. The sampling and data collection methodology is available on request from PEW. Available: http:// www.pewinternet.org/reports/chart.asp?img $1 / 4$ Daily_A6.htm.

Princeton Survey Research Associates. (April 2002). A matter of trust: What users want from Web Sites. A Report on Consumer Concerns About Credibility of Web Sites [WWW page]. A Consumer WebWatch research report prepared by Princeton Survey Research Associates, 1211 Connecticut Ave., N.W., Suite 305, Washington, DC 20036. Available: http://www.consumerwebwatch.org/news/ 1_TOC.htm.

Rainie, L., \& Horrigan, J. (2002). Holidays online - 2002: Email grows as a seasonal fixture and ecommerce advances [PDF file]. The Pew Internet \& American Life Project, Washington, DC. Available: http://www.pewinternet.org/reports/pdfs/PIP_Holidays_Online_2002.pdf.

Riegelsberger, J., \& Sasse, M. A. (2002). Face it: Photos don't make a web site trustworthy. Proceedings of CHI 2002 (pp. 272-273), Minneapolis, MN, April 20-25, ACM.

Riegelsberger, J., \& Sasse, M. A. (2001). Trustbuilders and trustbusters: The role of trust cues in interfaces to e-commerce applications [WWW page]. Paper presented at the 1st IFIP Conference on E-commerce, E-business, E-government. Available: http://www.cs.ucl.ac.uk/staff/J.Riegelsberger/trustbuilders_and_trustbusters.htm. 
Rotter, J. B. (1967). A new scale for the measurement of interpersonal trust. Journal of Personality, 35, 651-665.

Rotter, J. B. (1980). Interpersonal trust, trustworthiness, and gullibility. American Psychologist, 35(1), 1-7.

Sako, M. (1998). Does trust improve business performance? In C. Lane \& R. Bachmann (Eds.), Trust within and between organizations (pp. 88-117). New York: Oxford University Press.

Scheffelmaier, G. W., \& Vinsonhaler, J. F. (2002). A synthesis of research on the properties of effective internet commerce web sites. Journal of Computer Information Systems, Winter 2002-2003, 23-31.

Shankar, V., Urban, G. L., \& Sultan, F. (2002). Online trust: A stakeholder perspective, concepts, implications, and future direction. Journal of Strategic Information Systems, 11, 325-344.

Shneiderman, B. (2000). Designing trust into online experiences. Communication of the ACM, 43(12), 57 59.

Sirdeshmukh, D., Singh, J., \&Sabol, B. (2002). Consumer trust, value, and loyalty in relational exchanges. Journal of Marketing, 66(1), 15-37.

Stanford Persuasive Technology Lab. (October 2002). How do people evaluate a web site's credibility? Results from a large study [WWW page]. A Consumer WebWatch research report, prepared by Stanford Persuasive Technology Lab, Cordura Hall 226, Stanford University, Stanford, CA, 94305. Available: http://www.consumerwebwatch.org/news/report3_credibilityresearch/stanfordPTLabstract.htm.

Steinbruck, U., Schaumburg, H., Duda, S., \& Kruger, T. (2002). A picture says more than a thousand words - photographs as trust builders in e-commerce websites. In Conference Extended Abstracts on Human Factors in Computer Systems. Minneapolis, MN, USA.

Tan, X., Yen, D. C., \& Fang, X. (2002). Internet integrated customer relationship management: A key success factor for companies in the e-commerce arena. Journal of Computer Information Systems, Spring 2002, 77-86.

The Economist (February 3, 2001). Is there life in e-commerce? pp. 19-20.

Uzzi, B. (1997). Social structure and competition in interfirm networks: The paradox of embeddedness. Administration Science Quarterly, 42, 35-67.

Zhang, P., von Dran, G. M., Small, R. V., \& Barcellos, S. (1999). Websites that satisfy users: A theoretical framework for web user interface design and evaluation [PDF file]. IEEE Proceedings of the 32nd Hawaii International Conference on System Sciences (pp. 1-8). Available: http://www.computer.org/ proceedings/hicss/0001/00012/00012016.PDF. 